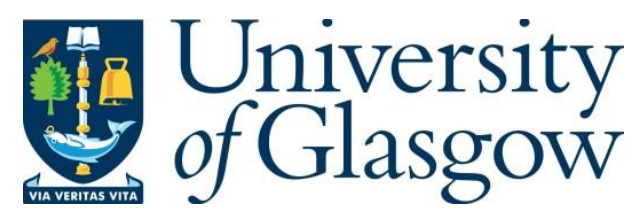

Mahinrad, S. et al. (2019) Spatial QRS-T angle and cognitive decline in older subjects. Journal of Alzheimer's Disease, 67(1), pp. 279-289.

There may be differences between this version and the published version. You are advised to consult the publisher's version if you wish to cite from it.

http://eprints.gla.ac.uk/180407/

Deposited on: 25 February 2019

Enlighten - Research publications by members of the University of Glasgow

http://eprints.gla.ac.uk 


\section{Spatial QRS-T angle and Cognitive Decline in Older Subjects}

Simin Mahinrad, MD, MSc ${ }^{\mathrm{a}, \mathrm{b}}$; Ian Ferguson, $\mathrm{MPH}^{\mathrm{c}}$; Peter W. Macfarlane, MD, DSc ${ }^{\mathrm{d}}$; Elaine

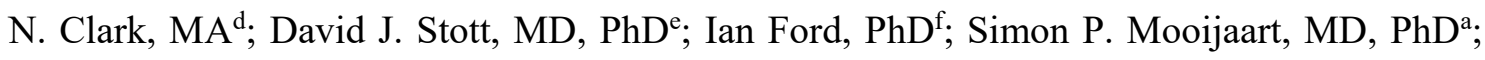
Stella Trompet, $\mathrm{PhD}^{\mathrm{a}}$; Diana van Heemst, $\mathrm{PhD}^{\mathrm{a}}$; J. Wouter Jukema, $\mathrm{MD}, \mathrm{PhD}^{\mathrm{g}}$ and Behnam Sabayan, MD, $\mathrm{PhD}^{\mathrm{a}, \mathrm{b}, *}$

a. Department of Internal Medicine, Gerontology and Geriatrics section, Leiden University Medical Center, Leiden, the Netherlands

b. Departments of Neurology, Northwestern University, Feinberg School of Medicine, Chicago, IL, USA

c. School of Medicine and Medical Science, University College Dublin, Dublin, Ireland

d. Institute of Health and Wellbeing, University of Glasgow, Glasgow, United Kingdom

e. Institute of Cardiovascular and Medical Sciences, University of Glasgow, Glasgow, United Kingdom

f. The Robertson Centre for Biostatistics, University of Glasgow, Glasgow, United Kingdom

g. Department of Cardiology, Leiden University Medical Center, Leiden, the Netherlands

*Correspondence: Behnam Sabayan, MD, PhD; Northwestern University-Feinberg School of Medicine. Address: 251 East Huron Street, Galter Suite 3-150, Chicago, IL 60611, USA.

Tel: (+1) 312-868-9432, Email: behnam.sabayan@,northwestern.edu 


\begin{abstract}
Background: An abnormally wide spatial QRS-T angle on an ECG is a marker of heterogeneity in electrical activity of cardiac ventricles and is linked with cardiovascular events. Growing evidence suggests that cardiac dysfunction might signal future cognitive decline.
\end{abstract}

Objective: In this study we investigated whether spatial QRS-T angle associates with future cognitive decline in older subjects at high cardiovascular risk.

Methods: We included 4172 men and women (mean age $75.2 \pm 3.3$ years) free of cardiac arrhythmias from the PROSPER cohort. Spatial QRS-T angle was calculated from baseline 12lead ECGs using a matrix transformation method. Cognitive function was assessed using 4 neuropsychological tests including Stroop test, letter-digit coding test, immediate and delayed picture word learning tests. Cognitive function was assessed at baseline and repeatedly during a mean follow-up time of 3.2 years. Using linear mixed models, we calculated the annual changes of cognitive scores in sex-specific thirds of spatial QRS-T angle.

Results: Participants with wider spatial QRS-T angle had a steeper decline in letter-digit coding test $(\beta=-0.0106, p=0.004)$, immediate picture-word learning test $(\beta=-0.0049, p=0.001)$ and delayed picture-word learning test $(\beta=-0.0055, \mathrm{p}=0.013)$. All associations were independent of arrhythmias, cardiovascular risk factors, comorbidities, medication use, cardiovascular events and other ECG abnormalities including QRS duration, QTc interval, T wave abnormalities and left ventricular hypertrophy.

Conclusion: Abnormal cardiac electrical activity characterized by wide spatial QRS-T angle associates with accelerated cognitive decline independent of conventional cardiovascular factors. These findings suggest a link between a non-traditional ECG measure of pre-clinical cardiac pathology and future cognitive decline.

Keywords: Spatial QRS-T angle; Cognitive function; Cardiac dysfunction; Old age 


\section{Introduction}

The electrical activity of the heart is generated by waves of myocardial depolarization and repolarization leading to a harmonized cardiac muscle contraction and relaxation [1]. Alterations in the sequence of ventricular depolarization and repolarization are not only associated with cardiovascular events $[2,3]$ but may also precede cerebrovascular events and increase risk of stroke [4]. Apart from overt cerebrovascular accidents, ventricular repolarization abnormality as measured by QT dispersion has been linked to cognitive impairment and Alzheimer's disease dementia [5]. Hence, early cardiac electrical abnormalities might signal future risk of cognitive impairment and such markers may assist in identification of high-risk populations.

The spatial QRS-T angle is a non-invasive subclinical marker of electrical activity of cardiac ventricles [6]. It quantifies the deviation in the direction of cardiac ventricular depolarization and repolarization in a three-dimensional space [7]. A wide spatial QRS-T angle reflects the pathophysiological changes in the ionic channels affecting the repolarization profiles, or structural abnormalities affecting the sequence of depolarization [8]. A wider spatial QRS-T angle has been associated with incident coronary heart disease [2], all-cause and cardiovascular mortality [9] and ischemic stroke [10]. Since a wide spatial QRS-T angle is a marker of greater inhomogeneity of electrical activity of cardiac ventricles, we aimed to study the independent link between spatial QRS-T angle and cognitive decline in older subjects at high risk of cardiovascular disease. 


\section{Methods}

\section{Study design}

The study population consists of the participants from the PROspective Study of Pravastatin in the Elderly at Risk (PROSPER). PROSPER was a multicenter randomized clinical trial which aimed to assess the effect of pravastatin in prevention of vascular events in older subjects with pre-existing cardiovascular risk factors or diseases [11]. In brief, a total of 5804 men and women at high cardiovascular risk (defined as being due to smoking, hypertension or diabetes mellitus) or with a history of vascular disease (defined as stable angina, intermittent claudication, stroke, transient ischemic attack, myocardial infarction [MI] and vascular surgery), aged 70 to 82 years, were enrolled from three collaborating centers in Ireland, Scotland and the Netherlands. The mean follow-up time was 3.2 years. The original PROSPER study was approved by the Medical Ethics Committees of the three collaborating centres and complied with the Declaration of Helsinki. All subjects gave written informed consent in accordance with the Declaration of Helsinki.

\section{Study participants}

From the baseline electrocardiogram (ECG) recordings, we excluded participants with missing spatial QRS-T angle measurements and those with evidence of atrial fibrillation, atrial flutter, ectopic atrial rhythms, supraventricular arrhythmias, junctional rhythms, intermittent conduction defect and other arrhythmias $(n=520)$. Furthermore, we included only participants with at least two cognitive measurements: the baseline and one follow-up measurement. Hence, a total of 4172 participants were included for analysis. Compared to the excluded participants, the included participants were younger and had a lower prevalence of cardiovascular risk factors and co-morbidities (Supplementary Table 1). We included participants from both treatment groups since it has been shown that treatment with pravastatin does not affect cognitive function [12].

\section{Spatial QRS-T angle measurement}

Standard 12-lead ECGs were recorded using a Burdick Eclipse 850i electrocardiograph in the resting supine position. All the ECGs were recorded in the morning of the first enrolment visit (at baseline) before initiation of statin treatment. A fully computerized automated method was used to ensure reproducibility of the measurements. The digital ECG recordings were transferred to the University of Glasgow ECG Core Lab in Scotland and interpreted using the University of Glasgow (Uni-G) ECG analysis program software [13]. The software provided 
an interpretation of the ECG recordings, Minnesota Codes, and numerous measurements including the QRS complex and T waves [13-15]. To calculate the spatial QRS-T angle, we first reconstructed the Frank XYZ vectocardiographic leads from the 12-lead ECG recordings using the inverse Dower method [16]. We then measured the spatial QRS-T angle as the angle between the maximum QRS vector and the maximum $\mathrm{T}$ vector. The maximum QRS and T vectors were defined as the point of maximum magnitude of the spatial QRS vector and the spatial T vector within the 3-dimensional QRS loop and T loop, respectively [6]. Since the cutpoint for spatial QRS-T angle has varied among previous studies [6], we first classified the spatial QRS-angle based on the sex-specific tertiles in three groups of low $\left(0^{\circ}-38^{\circ}\right.$ for women and $0^{\circ}-45^{\circ}$ for men), middle $\left(39^{\circ}-75^{\circ}\right.$ for women and $46^{\circ}-84^{\circ}$ for men $)$ and high $\left(76^{\circ}-180^{\circ}\right.$ for women and $85^{\circ}-180^{\circ}$ for men). Secondly, based on a cut-point used in previous studies for older subjects $[9,17]$, we classified the spatial QRS-T angle levels in three groups of normal $\left(0^{\circ}\right.$ to $\left.104^{\circ}\right)$, borderline $\left(105^{\circ}\right.$ to $\left.134^{\circ}\right)$, and abnormal $\left(135^{\circ}\right.$ to $\left.180^{\circ}\right)$.

The QT interval was calculated from the onset of QRS complex to the T offset and was corrected for heart rate (QTc interval) using the Hodges formula [18]. T wave abnormalities were defined as Minnesota Codes 5-1, 5-2 and 5-3 [14]. Left ventricular hypertrophy (LVH) was defined by using the Sokolow-Lyon voltage criteria [19].

\section{Cognitive function assessment}

In PROSPER, the mini-mental state examination test (MMSE) was used at baseline for screening purposes and participants with poor cognitive function (MMSE score <24) were excluded from enrolment in the study [20]. Four cognitive tests were used to assess different domains of cognitive function. The cognitive tests included the Stroop test, the letter-digit coding test (LDCT), immediate picture-word learning test (PLTi) and delayed picture-word learning test (PLTd). A detailed description of the cognitive assessments has been published elsewhere [20]. In brief, the Stroop test measures selective attention and reaction time. The outcome variable is the total number of seconds to complete the test. In contrast to the other cognitive tests used in this study, a higher score in Stroop test indicates worse performance. The LDCT measures the processing speed and the outcome variable is the total number of correct digits entered in 60 seconds; a higher score indicates better performance. The PLTi and PLTd tests measure immediate and delayed memory, respectively. The outcome variables are the accumulated number of correctly recalled pictures for the immediate and delayed trials; a higher score indicates better performance. Cognitive function was assessed at baseline, after 9 , 
18, 30 months and at the end of the study which varied between 36 and 48 months. During each visit, different versions of cognitive tests were used to avoid learning effects [20].

\section{Statistical analysis}

A p-value $<0.05$ was considered as statistically significant. Differences in baseline characteristics of participants in the three groups of spatial QRS-T angle were compared using the ANOVA test for continuous variables and Chi-squared test for categorical variables. Linear regression models were used to test the cross-sectional association between spatial QRS-T angle and cognitive function at baseline. The dependent variable was the score of each cognitive test at baseline. Using analysis of covariance, we calculated the adjusted mean score of cognitive tests in sex-specific thirds of spatial QRS-T angle. The Stroop test scores were log-transformed because they were not normally distributed. Linear mixed models (random regression model with random intercepts and slopes) were used to test the longitudinal association between spatial QRS-T angle and changes in cognitive scores over time. The models incorporated spatial QRS-T angle, time (in years) and the interaction term between time and spatial QRS-T angle. Subjects were defined as random factors and all other variables were defined as fixed factors. To assess the mean annual change of cognitive scores in thirds of spatial QRS-T angle, we computed the estimates of interaction between time and sex-specific thirds of spatial QRS-T angle using linear mixed models. To calculate the estimate of change in cognitive scores per 10 degree increase in spatial QRS-T angle, we divided the spatial QRS$\mathrm{T}$ angle levels by ten. All probability values were calculated using continuous values of spatial QRS-T angle. Both cross-sectional and longitudinal analyses were first adjusted for age, sex, education (age at which the participant left school), country of enrolment and version of cognitive tests where appropriate (model 1). In the next step, adjustment for cardiovascular diseases, cardiovascular risk factors and medication use (diuretics, beta-blockers, calcium channel blockers, angiotensin converting enzyme inhibitors [ACEI] and angiotensin receptors blockers [ARB]) were added (model 2). In longitudinal analysis, further adjustment for statin treatment groups was added in model 2. To test the effect of other ECG parameters on the longitudinal associations, adjustments for T wave abnormalities, QTc interval, QRS duration and LVH were added in model 3.

To test the effect of cardiovascular events on the longitudinal associations, a series of sensitivity analyses were performed in which we stratified for the participants according to who did and who did not develop incident atrial fibrillation, heart failure hospitalization, coronary 
events, fatal or non-fatal stroke or transient ischemic attack (TIA) and non-fatal MI during follow-up. To test whether the difference between participants who did and who did not develop cardiovascular events is significant, $p$ for interactions were calculated using linear mixed models. Furthermore, we tested the effect of baseline apolipoprotein e4 phenotype on longitudinal associations by stratifying participants in two groups of E4+ carriers (including $\mathrm{E}_{4 / 4}, \mathrm{E}_{3 / 4}$ and $\mathrm{E}_{2 / 4}$ ) and E4- carriers. Finally, we tested the effect of baseline cardiovascular comorbidities and use of anti-arrhythmic medications on longitudinal associations by excluding participants who had history of hypertension, history of diabetes mellitus, history of MI, history of stroke or TIA, and participants using anti-arrhythmic medications. 


\section{Results}

Of the 4172 participants in this study, the mean age was $75.2 \pm 3.3$ years and $1998(47.9 \%)$ participants were male. A total of 2593 (62.2\%) had history of hypertension, 427 (10.2\%) had history of diabetes mellitus, 541 (13.0\%) had history of MI and 430 (10.3\%) had history of stroke or TIA. The mean systolic blood pressure was $154.5 \pm 21.8 \mathrm{mmHG}$, mean diastolic blood pressure was $83.7 \pm 11.3 \mathrm{mmHG}$ and mean body mass index was $26.9 \pm 4.1 \mathrm{~kg} / \mathrm{m}^{2}$. Subjects with higher spatial QRS-T angle were slightly older, had higher prevalence of cardiovascular diseases and risk factors, were more likely to have T-wave abnormalities, had higher QTc interval and QRS duration, used ACEI more frequently and used beta-blockers less frequently (Table 1). Moreover, participants with higher spatial QRS-T angle were more likely to develop incident atrial fibrillation, heart failure hospitalization, coronary events, and nonfatal MI during follow-up period (Table 1).

Table 2 shows the cross-sectional association between spatial QRS-T and cognitive function at baseline. In model 1, higher spatial QRS-T angle was not associated with performance of participants in any of the cognitive tests at baseline. Full adjustments for cardiovascular risk factors, cardiovascular co-morbidities and medication use did not change the observed associations.

Table 3 and Figure 1 show the longitudinal association between spatial QRS-T angle and cognitive decline over a period of 3.2 years. In model 1, higher spatial QRS-T angle was significantly associated with a steeper decline in the LDCT $(\beta=-0.0106$; $p$-value $=0.004)$, PLTi $(\beta=0-0.0049 ; p$-value $=0.001)$ and PLTd $(\beta=-0.0055 ; p$-value $=0.013)$ scores during follow-up. After full adjustment for cardiovascular risk factors, cardiovascular co-morbidities and medication use, the mean annual change of cognitive scores in thirds of spatial QRS-T angle remained essentially the same (Table 3, model 2). Adjustment for baseline level of cognitive scores did not essentially change these results (data not shown). Furthermore, we found no significant difference in the annual change of cognitive scores between the low and middle thirds of spatial QRS-T angle (Supplementary Table 2).

To further explore the effect of other ECG parameters affecting the sequence of ventricular repolarization/depolarization on the longitudinal associations, adjustment for $\mathrm{T}$ wave abnormalities, QTc interval, QRS duration and LVH were added in model 3. Further adjustment for these parameters did not essentially change the results, meaning that higher 
spatial QRS-T angle remained significantly associated with a steeper decline in LDCT, PLTi and PLTd test scores (all p-values<0.05) (Table 3, model 3). Furthermore, we tested whether an interaction exists between spatial QRS-T angle and these ECG parameters in relation to cognitive function and found no significant interaction (all $\mathrm{p}$ for interactions $>0.05$ ). The estimate $(\beta)$ and $95 \%$ confidence intervals that were assessed using continuous levels of spatial QRS-T angle are presented in Supplementary Table 3. When we categorized the spatial QRS$\mathrm{T}$ angle according to a cut-point that is reported in literature (Normal: $0^{\circ}$ to $104^{\circ}$, Borderline: $105^{\circ}$ to $134^{\circ}$ and Abnormal: $135^{\circ}$ to $180^{\circ}$ ), the abnormal group was associated with a steeper decline in the Stroop, LDCT, PLTi and PLTd tests performances (Supplementary Table 4).

Over a period of 3.2 years, a total of 351 participants developed incident atrial fibrillation, 146 participants were hospitalized for heart failure, 424 participants developed coronary events, 279 participants developed stroke or TIA and 335 participants developed non-fatal MI. A total of 3235 subjects were free of these cardiovascular events during follow-up. Figure 2 shows the longitudinal association of spatial QRS-T angle and cognitive function stratified by incident cardiovascular events during follow-up. We did not observe a significant difference in annual changes of cognitive function between participants who did and those who did not develop incident atrial fibrillation, coronary events, stroke or TIA, heart failure hospitalization and nonfatal MI during follow-up (all $p$ for interactions $>0.05$ ). Furthermore, there was no interaction between baseline apolipoprotein e-4 carriers and spatial QRS-T angle during follow-up (Supplementary Table 5). Finally, when we excluded participants with additional cardiovascular co-morbidities at baseline and participants taking anti-arrhythmic medications, the longitudinal results did not change except that after exclusion of participants with history of hypertension ( $\mathrm{n}=1579,>37 \%$ of the population) higher spatial QRS-T angle was not associated with steeper decline in Stroop and LDCT tests performances (Supplementary Table $6)$. 


\section{Discussion}

Our findings suggest that a wide spatial QRS-T angle, as a reflection of greater heterogeneity in electrical activity of cardiac ventricles, associates with accelerated decline in cognitive function of older subjects at high cardiovascular risk. These associations were independent of arrhythmias, cardiovascular risk factor and co-morbidities, medication use, incident cardiovascular events and other ECG parameters.

Previous research has shown that different ECG-parameters measuring either the excitation or relaxation phase of the cardiac ventricles are related to cerebrovascular accidents and cognitive impairment. For example, men with pathologic Q waves suggesting unrecognized MI have a two-fold increased risk of dementia and carry a higher burden of cerebral small vessel disease [21]. Similarly, patients with Alzheimer's disease and mild cognitive impairment have higher values of QT dispersion and QT corrected dispersion [5]. Our current study suggests that an abnormal spatial QRS-T angle might precede the decline in cognitive function in a large cohort of older adults at high cardiovascular risk. Furthermore, the persistence of longitudinal associations in subjects without cardiac arrhythmias suggests that even subtle alterations in the ventricular electrical activity are linked to cognitive decline.

The observed association between spatial QRS-T angle and cognitive decline can be explained through a number of pathophysiological mechanisms. First, a wide spatial QRS-T angle and cognitive decline may both reflect cardiovascular damage and hence share a common cause. Previous research has shown that spatial QRS-T angle is a strong non-invasive predictor of cardiovascular morbidity and mortality [2, 22, 23] and a wide angle is linked with higher electric instability of the cardiac ventricles that might increase the risk of cardiac arrhythmias and ischemia [7]. The role of cardiovascular risk factors and diseases in development of cognitive impairment is well established [24]. In line with this, our results show that subjects with higher spatial QRS-T angle have higher prevalence of cardiovascular co-morbidities and are more likely to develop incident cardiovascular events during follow-up. Furthermore, exclusion of subjects with a history of hypertension at baseline attenuated the longitudinal relation of spatial QRS-T angle and executive function as measured by Stroop and LDCT tests. However, the relation between spatial QRS-T angle and memory function was independent of measured cardiovascular co-morbidities and incident cardiovascular events during follow-up. An abnormal spatial QRS-T angle might reflect cardiac changes that results in hemodynamic stress and altered brain perfusion, which might in turn lead to global cognitive decline [25]. In 
line with this, a wide QRS-T angle have been associated with cardiac abnormalities such as ventricular remodelling, diastolic dysfunction, impaired ionic channel and calcium homeostasis in heart failure patients [26]. Moreover, a wide QRS-T angle has been linked to worse left ventricular myocardial performance index in diabetic patients free of cardiovascular diseases [27]. Such alterations may cause subtle hemodynamic instability, which may over time, lead to cerebral small vessel disease and ultimately to parenchymal damage manifesting as cognitive impairment $[24,28]$. Nevertheless, we cannot rule out the effect of residual confounding and unmeasured cardiovascular factors in our study, which might affect both cognitive function and spatial QRS-T angle. Finally, it is also possible that a wide QRS-T angle mirrors the already established cerebrovascular damage in the brain which may in turn contribute to cognitive impairment [10].

It is important to mention that the spatial QRS-T angle is superior to other traditional ECG parameters measuring cardiac electrical activity since it quantifies the spatial aspects of ventricular action potential that are not measured by other ECG-parameters [17]. Furthermore, spatial QRS-T angle is a more robust parameter since it is less susceptible to measurement errors and noises due to determination of the T wave end on the surface of ECG $[7,29]$. Other ECG measures of ventricular electrical activity such as QT dispersion and QTc interval are highly dependent on the determination of ECG wave points [30]. Moreover, the spatial QRS$\mathrm{T}$ angle is distinct from other well-known markers of cardiac dysfunction such as troponin and B-type natriuretic peptide. Such plasma markers of cardiac dysfunction are released from cardiac muscles in response to cardiac wall stretch and/or cardiac muscle damage [31]. However, the spatial QRS-T angle is suggested to be increased as a result of subtle cardiac ionic channel disturbances and/or cardiac structural abnormalities [7]. As such, spatial QRS-T angle might be a non-invasive marker for detection of subtle cardiac abnormalities in an early stage $[23,32]$.

In our analysis, we did not find a cross-sectional association between spatial QRS-T angle and cognitive function at baseline. This might be due to the characteristics of participants in the original PROSPER cohort in which subjects with poor cognitive function were excluded [11]. Since our population consists of older subjects with a fairly preserved cognitive function at baseline, the observed association between QRS-T angle and cognitive function might be underestimated. Nevertheless, a wide spatial QRS-angle was associated with a significant decline in all four cognitive tests during follow-up, strengthening the temporal order of the 
associations. Furthermore, the threshold for abnormal spatial QRS-T angle varied among studies $[17,23,33]$ and there is no established cut-off point. When we repeated our analysis using a cut-off point from previous literature [9, 17], the results did not essentially change. Future research should determine the optimal age and gender specific threshold for abnormal spatial QRS-T angle.

The strengths of this study include the large sample size (more than 4000 participants), prospective multicentre design and the use of different cognitive tests assessing various domains of cognitive function. Furthermore, the non-invasive nature of ECG makes the QRS$\mathrm{T}$ angle a suitable tool for use in clinical practice and supports its use for cardiovascular prevention strategies as well as efforts to prevent cognitive decline. Although measurement of spatial QRS-T angle requires a computer program, the implementation of this program using modern electrocardiographs is quite easy [17]. One limitation is that the participants had preexisting cardiovascular risk factors or disease which might limit generalizability of our findings to a healthy older population. Another limitation is that PROSPER had a relatively short duration of follow-up which might result in small magnitude of associations and limit the clinical significance of our findings. Of note, although the magnitude of associations were small, the effect estimates were comparable with the effect estimates of left ventricular hypertrophy and apolipoprotein E4 in relation to cognitive decline in the same population [34, 35]. Moreover, only $10 \%$ of the population developed incident events during follow-up which might have under-powered our analysis in finding moderating effects of cardiovascular events on the reported associations. Finally, this was a secondary analysis of a randomized-controlled trial and was not designed to investigate a causal association between ECG abnormalities and cognitive decline.

In conclusion, we found that wider spatial QRS-T angle as a reflection of electrical instability in cardiac ventricles associates with accelerated cognitive decline independent of several conventional cardiovascular risk factors and comorbidities. These findings provide insight into the link between pre-clinical cardiac pathologies and development of cognitive decline in future. Future work should investigate the prognostic accuracy of a widened QRS-T angle and future cognitive decline, with the aim of early intervention into subtle cardiovascular abnormality in order to prevent cerebrovascular alterations and cognitive impairment. 


\section{Acknowledgments:}

BS and SM were partially supported by a grant from CardioVascular Research Netherlands (CVON) Heart-Brain Connection (HBC) consortium.

\section{Funding Sources:}

The original PROSPER clinical trial was funded by an investigator-initiated grant from BristolMyers Squibb, USA. The company had no involvement in the design and conduct of the study; collection, management, analysis, and interpretation of the data; preparation, review, and approval of the manuscript; or decision to submit the manuscript for publication

\section{Conflict of Interest:}

None 


\section{References}

[1] Katz AM (2010) Physiology of the Heart, Lippincott Williams \& Wilkins.

[2] Rautaharju PM, Kooperberg C, Larson JC, LaCroix A (2006) Electrocardiographic abnormalities that predict coronary heart disease events and mortality in postmenopausal women: the Women's Health Initiative. Circulation 113, 473-480.

[3] Pietrasik G, Goldenberg I, Zdzienicka J, Moss AJ, Zareba W (2007) Prognostic significance of fragmented QRS complex for predicting the risk of recurrent cardiac events in patients with Q-wave myocardial infarction. Am J Cardiol 100, 583-586.

[4] Soliman EZ, Howard G, Cushman M, Kissela B, Kleindorfer D, Le A, Judd S, McClure LA, Howard VJ (2012) Prolongation of QTc and risk of stroke: The REGARDS (REasons for Geographic and Racial Differences in Stroke) study. J Am Coll Cardiol 59, 1460-1467.

[5] Zulli R, Nicosia F, Borroni B, Agosti C, Prometti P, Donati P, De Vecchi M, Romanelli G, Grassi V, Padovani A (2005) QT dispersion and heart rate variability abnormalities in Alzheimer's disease and in mild cognitive impairment. J Am Geriatr Soc 53, 2135-2139.

[6] Oehler A, Feldman T, Henrikson CA, Tereshchenko LG (2014) QRS-T angle: a review. Ann Noninvasive Electrocardiol 19, 534-542.

[7] Voulgari C, Tentolouris N (2009) Assessment of the Spatial QRS-T Angle by Vectorcardiography: Current Data and Perspectives. Curr Cardiol Rev 5, 251-262.

[8] Aro AL, Huikuri HV, Tikkanen JT, Junttila MJ, Rissanen HA, Reunanen A, Anttonen O (2012) QRS-T angle as a predictor of sudden cardiac death in a middle-aged general population. Europace 14, 872-876.

[9] Whang W, Shimbo D, Levitan EB, Newman JD, Rautaharju PM, Davidson KW, Muntner P (2012) Relations between QRS $\mid \mathrm{T}$ angle, cardiac risk factors, and mortality in the third National Health and Nutrition Examination Survey (NHANES III). Am J Cardiol 109, 981-987.

[10] Gandhi K, Aronow WS, Desai H, Palaniswamy C, Singh T, Amin H, Sharma M, Lai HM (2010) Patients with ischemic stroke have a higher prevalence of a planar QRS-T angle $>90$ degrees than patients with transient ischemic attack. Med Sci Monit 16, CR588-592.

[11] Shepherd J, Blauw GJ, Murphy MB, Cobbe SM, Bollen EL, Buckley BM, Ford I, Jukema JW, Hyland M, Gaw A, Lagaay AM, Perry IJ, Macfarlane PW, Meinders AE, Sweeney BJ, Packard CJ, Westendorp RG, Twomey C, Stott DJ (1999) The design of a prospective study of Pravastatin in the Elderly at Risk (PROSPER). PROSPER Study Group. PROspective Study of Pravastatin in the Elderly at Risk. Am J Cardiol 84, 1192-1197.

[12] Trompet S, van Vliet P, de Craen AJ, Jolles J, Buckley BM, Murphy MB, Ford I, Macfarlane PW, Sattar N, Packard CJ, Stott DJ, Shepherd J, Bollen EL, Blauw GJ, Jukema JW, Westendorp RG (2010) Pravastatin and cognitive function in the elderly. Results of the PROSPER study. $J$ Neurol 257, 85-90.

[13] Macfarlane P, Devine B, Clark E (2005) in Computers in Cardiology, 2005 IEEE, pp. 451-454.

[14] Macfarlane PW, Latif S (1996) Automated serial ECG comparison based on the Minnesota code. $J$ Electrocardiol 29 Suppl, 29-34.

[15] Macfarlane PW, Murray H, Sattar N, Stott DJ, Ford I, Buckley B, Jukema JW, Westendorp RG, Shepherd $\mathrm{J}$ (2011) The incidence and risk factors for new onset atrial fibrillation in the PROSPER study. Europace 13, 634-639. 
[16] Edenbrandt L, Pahlm O (1988) Vectorcardiogram synthesized from a 12-lead ECG: superiority of the inverse Dower matrix. J Electrocardiol 21, 361-367.

[17] Kardys I, Kors JA, van der Meer IM, Hofman A, van der Kuip DA, Witteman JC (2003) Spatial QRS-T angle predicts cardiac death in a general population. Eur Heart J 24, 1357-1364.

[18] Luo S, Michler K, Johnston P, Macfarlane PW (2004) A comparison of commonly used QT correction formulae: the effect of heart rate on the QTc of normal ECGs. J Electrocardiol 37 Suppl, 81-90.

[19] Wagner GS, Macfarlane P, Wellens H, Josephson M, Gorgels A, Mirvis DM, Pahlm O, Surawicz B, Kligfield P, Childers R, Gettes LS, Bailey JJ, Deal BJ, Gorgels A, Hancock EW, Kors JA, Mason JW, Okin P, Rautaharju PM, van Herpen G, American Heart Association E, Arrhythmias Committee CoCC, American College of Cardiology F, Heart Rhythm S (2009) AHA/ACCF/HRS recommendations for the standardization and interpretation of the electrocardiogram: part VI: acute ischemia/infarction: a scientific statement from the American Heart Association Electrocardiography and Arrhythmias Committee, Council on Clinical Cardiology; the American College of Cardiology Foundation; and the Heart Rhythm Society: endorsed by the International Society for Computerized Electrocardiology. Circulation 119, e262-270.

[20] Houx PJ, Shepherd J, Blauw GJ, Murphy MB, Ford I, Bollen EL, Buckley B, Stott DJ, Jukema W, Hyland M, Gaw A, Norrie J, Kamper AM, Perry IJ, MacFarlane PW, Meinders AE, Sweeney BJ, Packard CJ, Twomey C, Cobbe SM, Westendorp RG (2002) Testing cognitive function in elderly populations: the PROSPER study. PROspective Study of Pravastatin in the Elderly at Risk. J Neurol Neurosurg Psychiatry 73, 385-389.

[21] Ikram MA, van Oijen M, de Jong FJ, Kors JA, Koudstaal PJ, Hofman A, Witteman JC, Breteler MM (2008) Unrecognized myocardial infarction in relation to risk of dementia and cerebral small vessel disease. Stroke 39, 1421-1426.

[22] Rautaharju PM, Kooperberg C, Larson JC, LaCroix A (2006) Electrocardiographic predictors of incident congestive heart failure and all-cause mortality in postmenopausal women: the Women's Health Initiative. Circulation 113, 481-489.

[23] Yamazaki T, Froelicher VF, Myers J, Chun S, Wang P (2005) Spatial QRS-T angle predicts cardiac death in a clinical population. Heart Rhythm 2, 73-78.

[24] van Buchem MA, Biessels GJ, Brunner la Rocca HP, de Craen AJ, van der Flier WM, Ikram MA, Kappelle LJ, Koudstaal PJ, Mooijaart SP, Niessen W, van Oostenbrugge R, de Roos A, van Rossum AC, Daemen MJ (2014) The heart-brain connection: a multidisciplinary approach targeting a missing link in the pathophysiology of vascular cognitive impairment. J Alzheimers Dis 42 Suppl 4, S443-451.

[25] Jefferson AL, Himali JJ, Beiser AS, Au R, Massaro JM, Seshadri S, Gona P, Salton CJ, DeCarli C, O'Donnell CJ, Benjamin EJ, Wolf PA, Manning WJ (2010) Cardiac index is associated with brain aging: the Framingham Heart Study. Circulation 122, 690-697.

[26] Selvaraj S, Ilkhanoff L, Burke MA, Freed BH, Lang RM, Martinez EE, Shah SJ (2014) Association of the frontal QRS-T angle with adverse cardiac remodeling, impaired left and right ventricular function, and worse outcomes in heart failure with preserved ejection fraction. J Am Soc Echocardiogr 27, 74-82 e72. 
[27] Voulgari C, Tentolouris N, Moyssakis I, Dilaveris P, Gialafos E, Papadogiannis D, Votteas V, Cokkinos DV, Stefanadis C, Katsilambros N (2006) Spatial QRS-T angle: association with diabetes and left ventricular performance. Eur J Clin Invest 36, 608-613.

[28] van der Velpen IF, Yancy CW, Sorond FA, Sabayan B (2017) Impaired Cardiac Function and Cognitive Brain Aging. Can J Cardiol 33, 1587-1596.

[29] Kors JA, van Herpen G, van Bemmel JH (1999) QT dispersion as an attribute of T-loop morphology. Circulation 99, 1458-1463.

[30] Statters DJ, Malik M, Ward DE, Camm AJ (1994) QT dispersion: problems of methodology and clinical significance. J Cardiovasc Electrophysiol 5, 672-685.

[31] Amsterdam EA, Wenger NK, Brindis RG, Casey DE, Jr., Ganiats TG, Holmes DR, Jr., Jaffe AS, Jneid H, Kelly RF, Kontos MC, Levine GN, Liebson PR, Mukherjee D, Peterson ED, Sabatine MS, Smalling RW, Zieman SJ, American College of C, American Heart Association Task Force on Practice G, Society for Cardiovascular A, Interventions, Society of Thoracic S, American Association for Clinical C (2014) 2014 AHA/ACC Guideline for the Management of Patients with Non-ST-Elevation Acute Coronary Syndromes: a report of the American College of Cardiology/American Heart Association Task Force on Practice Guidelines. J Am Coll Cardiol 64, e139-228.

[32] Voulgari C, Pagoni S, Tesfaye S, Tentolouris N (2013) The spatial QRS-T angle: implications in clinical practice. Curr Cardiol Rev 9, 197-210.

[33] Zhang ZM, Prineas RJ, Case D, Soliman EZ, Rautaharju PM, Group AR (2007) Comparison of the prognostic significance of the electrocardiographic QRS/T angles in predicting incident coronary heart disease and total mortality (from the atherosclerosis risk in communities study). Am J Cardiol 100, 844849 .

[34] Mahinrad S, Vriend AE, Jukema JW, van Heemst D, Sattar N, Blauw GJ, Macfarlane PW, Clark EN, de Craen AJM, Sabayan B (2017) Left Ventricular Hypertrophy and Cognitive Decline in Old Age. J Alzheimers Dis 58, 275-283.

[35] Packard CJ, Westendorp RG, Stott DJ, Caslake MJ, Murray HM, Shepherd J, Blauw GJ, Murphy MB, Bollen EL, Buckley BM, Cobbe SM, Ford I, Gaw A, Hyland M, Jukema JW, Kamper AM, Macfarlane PW, Jolles J, Perry IJ, Sweeney BJ, Twomey C, Prospective Study of Pravastatin in the Elderly at Risk G (2007) Association between apolipoprotein E4 and cognitive decline in elderly adults. J Am Geriatr Soc 55, 1777-1785. 
Table 1. Baseline characteristics of participants in thirds of Spatial QRS-T angle

\begin{tabular}{|c|c|c|c|c|}
\hline & \multicolumn{3}{|c|}{ Spatial QRS-T angle thirds } & \multirow[b]{2}{*}{ p-value } \\
\hline & $\begin{array}{c}\text { Low } \\
n=1383\end{array}$ & $\begin{array}{l}\text { Middle } \\
n=1393\end{array}$ & $\begin{array}{c}\text { High } \\
n=1396\end{array}$ & \\
\hline \multicolumn{5}{|l|}{ Demographics } \\
\hline Age, years, mean (SD) & $75.04(3.29)$ & $75.09(3.30)$ & $75.33(3.37)$ & 0.049 \\
\hline Age left school, years, mean (SD) & $15.22(2.15)$ & $15.25(2.11)$ & $15.12(2.08)$ & 0.253 \\
\hline Country, n (\%) & & & & 0.262 \\
\hline Scotland & $608(44.0)$ & $586(42.1)$ & $624(44.7)$ & \\
\hline Ireland & $489(35.4)$ & $490(35.2)$ & $502(36.0)$ & \\
\hline Netherlands & $286(20.7)$ & $317(22.8)$ & $270(19.3)$ & \\
\hline \multicolumn{5}{|c|}{ Cardiovascular diseases and risk factors } \\
\hline History of vascular disease, $\mathrm{n}(\%)$ & $543(39.3)$ & $568(40.8)$ & $713(51.1)$ & $<0.001$ \\
\hline History of stroke or TIA, n (\%) & $126(9.1)$ & $140(10.1)$ & $164(11.7)$ & 0.068 \\
\hline History of MI, n (\%) & $116(8.4)$ & $156(11.2)$ & $269(19.3)$ & $<0.001$ \\
\hline History of DM, n (\%) & $123(8.9)$ & $134(9.6)$ & $170(12.2)$ & 0.011 \\
\hline History of hypertension, $\mathrm{n}(\%)$ & $841(60.8)$ & $883(63.4)$ & $869(62.2)$ & 0.373 \\
\hline $\mathrm{LVH}, \mathrm{n}(\%)^{*}$ & $41(3.0)$ & $112(8.0)$ & $157(11.3)$ & $<0.001$ \\
\hline BMI, $\mathrm{kg} / \mathrm{m}^{2}$, mean (SD) & $26.87(4.17)$ & $26.69(3.97)$ & $27.19(4.25)$ & 0.006 \\
\hline $\mathrm{SBP}, \mathrm{mmHG}$, mean (SD) & $152.17(21.48)$ & $154.78(21.51)$ & $156.58(22.33)$ & $<0.001$ \\
\hline DBP, mmHG, mean (SD) & $83.09(11.40)$ & $83.67(10.74)$ & $84.35(11.61)$ & 0.012 \\
\hline Current smoking, n (\%) & $373(27.0)$ & $362(26.0)$ & $351(25.1)$ & 0.547 \\
\hline \multicolumn{5}{|l|}{ ECG parameters } \\
\hline Heart rate, beats/min, mean (SD) & $65.70(11.06)$ & $65.48(11.47)$ & $66.67(11.62)$ & 0.014 \\
\hline $\mathrm{T}$ wave abnormality, $\mathrm{n}(\%) \dagger$ & $184(13.3)$ & $353(25.3)$ & $560(40.1)$ & $<0.001$ \\
\hline QTc interval, sec, mean (SD) & $0.424(0.02)$ & $0.426(0.03)$ & $0.433(0.03)$ & $<0.001$ \\
\hline QRS duration, sec, mean (SD) & $0.095(0.02)$ & $0.094(0.01)$ & $0.105(0.02)$ & $<0.001$ \\
\hline \multicolumn{5}{|l|}{ Medications } \\
\hline Beta-blocker, n (\%) & $413(29.9)$ & $379(27.2)$ & $325(23.3)$ & $<0.001$ \\
\hline Diuretic, n (\%) & $538(38.9)$ & $561(40.3)$ & $557(39.9)$ & 0.747 \\
\hline ACE inhibitor, $n(\%)$ & $188(13.6)$ & $208(14.9)$ & $268(19.2)$ & $<0.001$ \\
\hline ARB, n (\%) & $26(1.9)$ & $24(1.7)$ & $39(2.8)$ & 0.107 \\
\hline Calcium channel blocker, $\mathrm{n}(\%)$ & $324(23.4)$ & $350(25.1)$ & $376(26.9)$ & 0.103 \\
\hline \multicolumn{5}{|c|}{ Incident cardiovascular events during follow-up } \\
\hline Atrial fibrillation, $\mathrm{n}(\%)$ & $105(7.6)$ & $105(7.5)$ & $141(10.1)$ & 0.021 \\
\hline HF hospitalization, $\mathrm{n}(\%)$ & $34(2.5)$ & $37(2.7)$ & $75(5.4)$ & $<0.001$ \\
\hline Coronary events, $\mathrm{n}(\%)$ & $110(8.0)$ & $123(8.8)$ & $191(13.7)$ & $<0.001$ \\
\hline Non-fatal MI, n (\%) & $99(7.2)$ & $99(7.1)$ & $137(9.8)$ & 0.011 \\
\hline Stroke or TIA, n (\%) & $89(6.4)$ & $91(6.5)$ & $99(7.1)$ & 0.756 \\
\hline
\end{tabular}

Cut-points for low, middle and high groups for women are: $0^{\circ}-38^{\circ}, 39^{\circ}-75^{\circ}, 76^{\circ}-180^{\circ}$, respectively; and for men: $0^{\circ}-45^{\circ}, 46^{\circ}-84^{\circ}, 85^{\circ}-180^{\circ}$, respectively. ${ }^{*} \mathrm{LVH}$ : LVH based on Sokolow-Lyon index cut points $(\geq 3500 \mu \mathrm{V})$; $\dagger \mathrm{T}$ wave abnormality: Minnesota code 5-1, 5-2 and 5-3. Abbreviations: SD: Standard Deviation; n: Number; TIA: Transient Ischemic Attack; MI: Myocardial Infarction; DM: Diabetes Mellitus; LVH: Left Ventricular Hypertrophy; BMI: Body Mass Index; SBP: Systolic Blood Pressure; DBP: Diastolic Blood Pressure; ACE inhibitors: Angiotensin Converting Enzyme inhibitors; ARBs: Angiotensin Receptor Blockers; HF: Heart Failure. 
Table 2. Cognitive function in relation to spatial QRS-T angle at baseline

\begin{tabular}{|c|c|c|c|c|}
\hline & \multicolumn{3}{|c|}{ Spatial QRS-T angle thirds } & \multirow[b]{2}{*}{ p-value* } \\
\hline & $\begin{array}{c}\text { Low } \\
n=1383\end{array}$ & $\begin{array}{l}\text { Middle } \\
\mathrm{n}=1393\end{array}$ & $\begin{array}{c}\text { High } \\
n=1396\end{array}$ & \\
\hline \multicolumn{5}{|c|}{ Stroop, seconds, mean (SE): } \\
\hline Model 1 & $63.45(0.61)$ & $62.90(0.61)$ & $64.64(0.61)$ & 0.049 \\
\hline Model 2 & $66.04(1.57)$ & $65.46(1.57)$ & $66.84(1.52)$ & 0.166 \\
\hline \multicolumn{5}{|c|}{ LDCT, digits coded, mean (SE): } \\
\hline Model 1 & $24.21(0.18)$ & $24.06(0.18)$ & $23.87(0.18)$ & 0.064 \\
\hline Model 2 & $23.21(0.45)$ & $23.05(0.45)$ & $22.99(0.44)$ & 0.171 \\
\hline \multicolumn{5}{|c|}{ PLTi, pictures remembered, mean (SE): } \\
\hline Model 1 & $9.50(0.05)$ & $9.55(0.05)$ & $9.46(0.05)$ & 0.299 \\
\hline Model 2 & $9.40(0.12)$ & $9.46(0.12)$ & $9.39(0.12)$ & 0.436 \\
\hline \multicolumn{5}{|c|}{ PLTd, pictures remembered, mean (SE): } \\
\hline Model 1 & $10.38(0.07)$ & $10.47(0.07)$ & $10.35(0.07)$ & 0.530 \\
\hline Model 2 & $10.25(0.17)$ & $10.35(0.17)$ & $10.28(0.17)$ & 0.876 \\
\hline
\end{tabular}

*p-values were calculated using continuous values of spatial QRS-T angle

Model 1: adjusted for age, sex, country, education and version of cognitive tests where applicable; Model 2: adjusted for all the variables in model $1+$ history of vascular disease, history of diabetes, systolic and diastolic blood pressure, body mass index, smoking status and antihypertensive medications. Abbreviations: SE: Standard Error; LDCT: Letter Digit Coding Test; PLTi: Picture-Word Learning Test immediate; PLTd: Picture-Word Learning Test delayed. 
Table 3. Cognitive function in relation to spatial QRS-T angle during follow-up

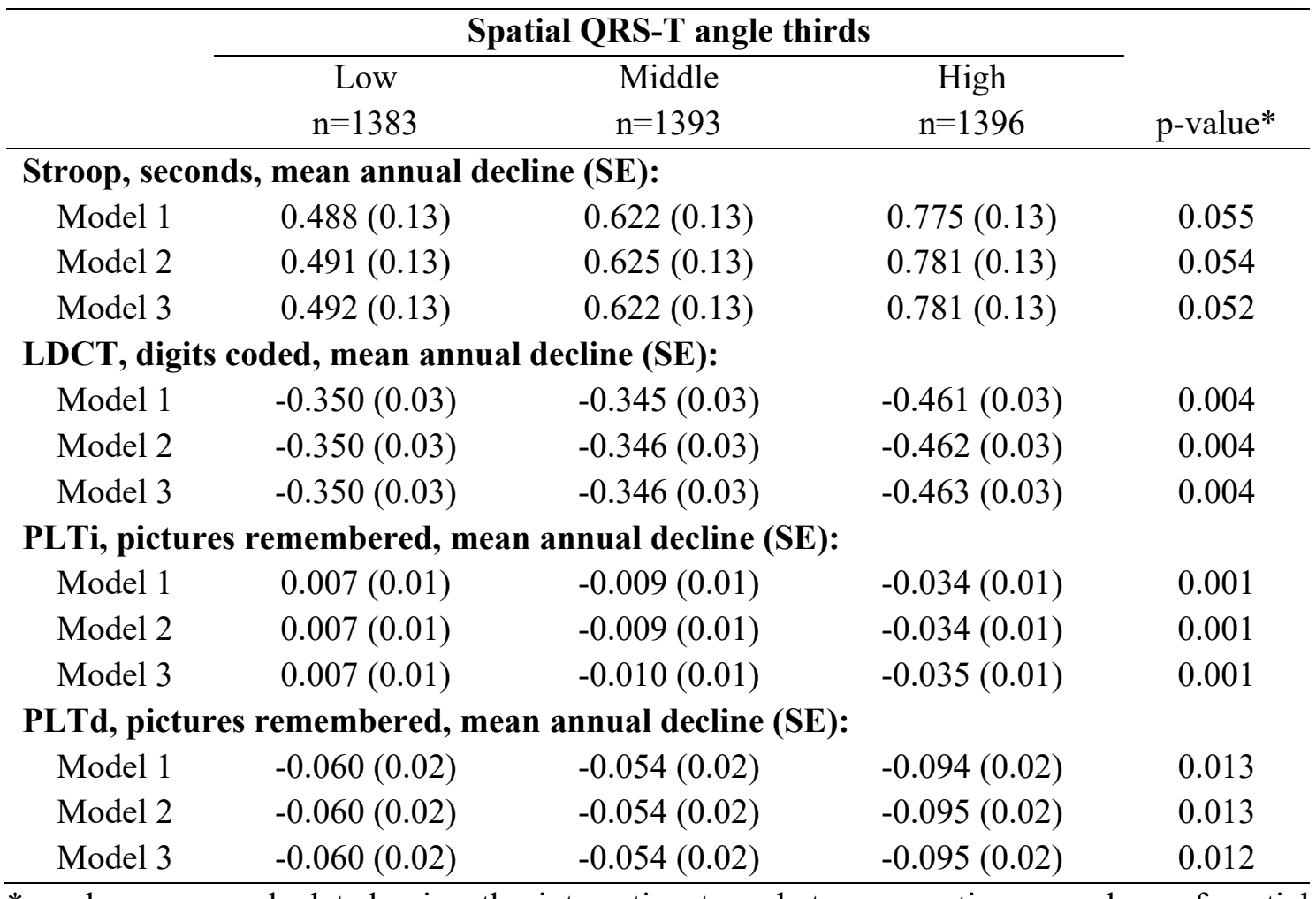

*p-values were calculated using the interaction term between continuous values of spatial QRS-T angle and time.

Means represent the mean annual decline in the score of each cognitive test.

Model 1: adjusted for age, sex, country, education and version of cognitive tests where applicable; Model 2: adjusted for all the variables in model 1+ history of vascular disease, history of diabetes, systolic and diastolic blood pressure, body mass index, smoking status, antihypertensive medications and statin treatment groups. Model 3: adjusted for all the variables in model $2+\mathrm{LVH}, \mathrm{T}$ wave abnormalities, QTc interval and QRS duration. Abbreviations: SE: Standard Error; LDCT: Letter Digit Coding Test; PLTi: Picture-Word Learning Test immediate; PLTd: Picture-Word Learning Test delayed. 
Stroop-Colour-Word test

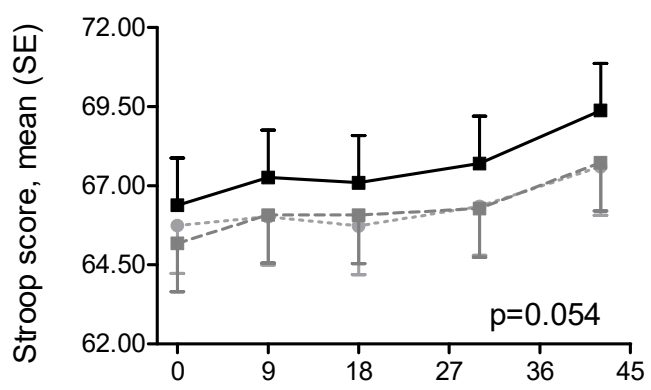

Picture Learning test immediate

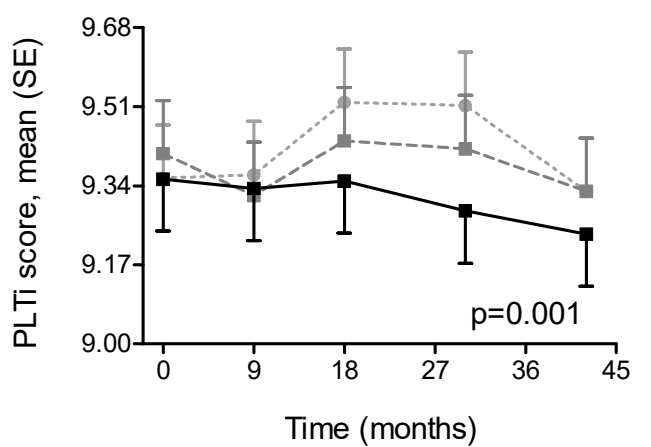

Letter-Digit Coding test

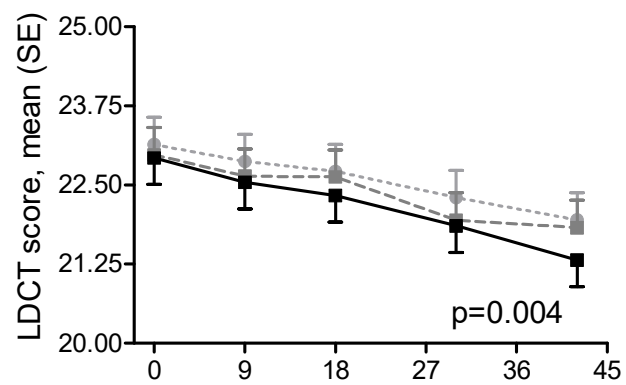

Picture Learning test delayed

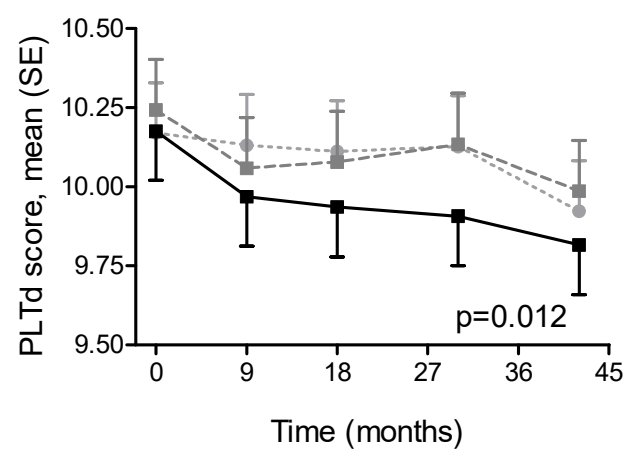

- QRST low $\quad-$ - QRST middle $\rightarrow$ QRST high

Figure 1. Cognitive function in relation to spatial QRS-T angle during follow-up. Data represent mean (standard error) decline in the score of each cognitive test in three groups of spatial QRS-T angle. The time point at the end of the study is the mean of end time points (36 to 48 months). Analyses were adjusted for age, country, education, version of cognitive tests where applicable, history of diabetes, history of vascular disease, body mass index, smoking status, systolic blood pressure, diastolic blood pressure, antihypertensive medications and statin treatment groups. 
Stroop-Colour-Word test

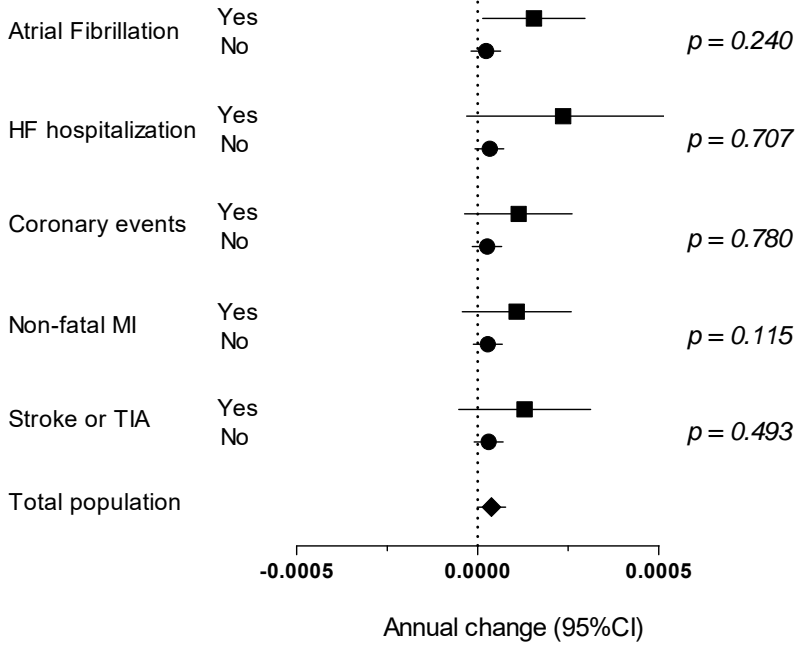

Picture Learning test immediate

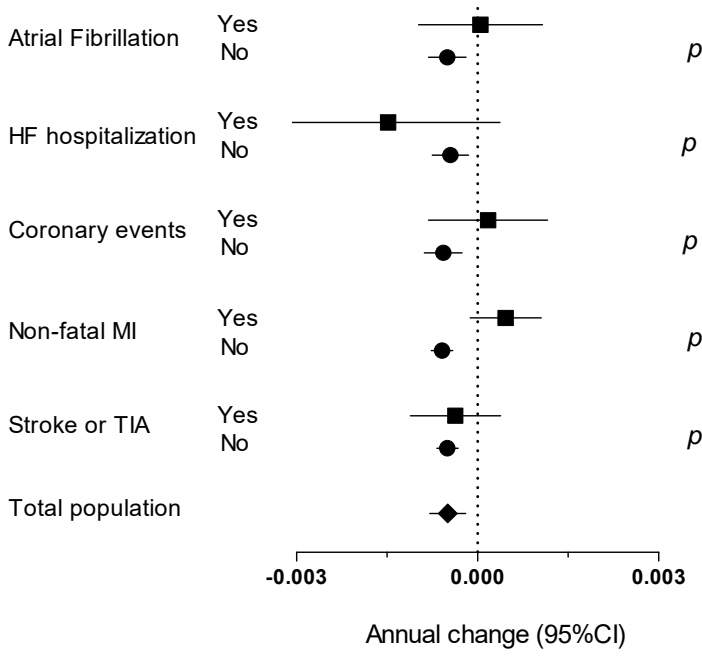

Letter-Digit Coding test

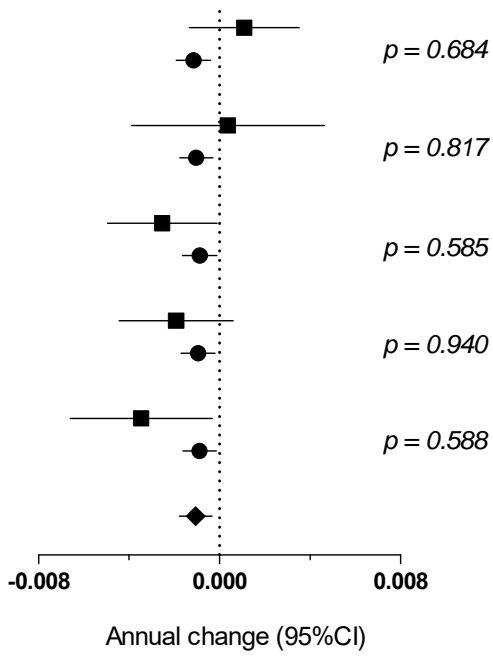

Picture Learning test delayed

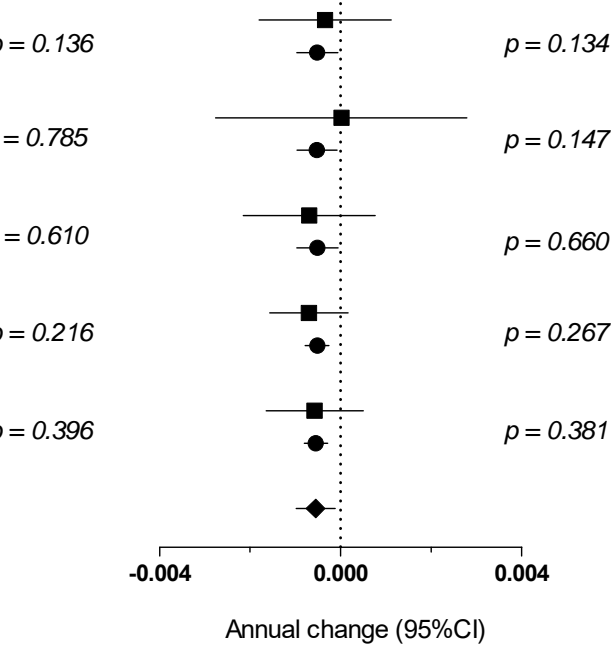

Figure 2. Association of spatial QRS-T angle and annual changes of cognitive function stratified for cardiovascular events during follow-up. Data represent annual change (95\% confidence interval) in cognitive function per each unit (degree) increase in spatial QRS-T angle (the $\mathrm{X}$ axis), stratified for subjects who did and those who did not develop cardiovascular events during follow-up. Dark circles and squares correspond to the annual change (estimate) and the lines correspond to the $95 \%$ confidence intervals. P-values show the $\mathrm{p}$ for interaction. Analyses were performed in the fully adjusted model. Abbreviation: MI: myocardial infarction; HF: heart failure hospitalization and TIA: transient ischemic attack 


\section{Supplementary Data}

Supplementary Table 1. Baseline characteristics of included and excluded participants

\begin{tabular}{|c|c|c|c|}
\hline Characteristics & $\begin{array}{c}\text { Included } \\
\mathrm{n}=4172\end{array}$ & $\begin{array}{c}\text { Excluded } \\
n=1632\end{array}$ & p-value \\
\hline \multicolumn{4}{|l|}{ Socio-demographics: } \\
\hline Age, years, mean (SD) & $75.2(3.3)$ & $75.8(3.4)$ & $<0.001$ \\
\hline Male, n (\%) & $1998(47.9)$ & $806(49.4)$ & 0.305 \\
\hline Age left school, years, mean (SD) & $15.2(2.1)$ & $15.0(1.8)$ & $<0.001$ \\
\hline \multicolumn{4}{|l|}{ Cardiovascular risk factors: } \\
\hline History of vascular disease, $\mathrm{n}(\%)$ & $1824(43.7)$ & $741(45.4)$ & 0.245 \\
\hline History of stroke or TIA, n (\%) & $430(10.0)$ & $219(13.4)$ & 0.001 \\
\hline History of MI, n (\%) & $541(13.0)$ & $235(14.4)$ & 0.097 \\
\hline History of DM, n (\%) & $427(10.2)$ & $196(12.0)$ & 0.050 \\
\hline $\mathrm{SBP}, \mathrm{mmHg}$, mean (SD) & $154.5(21.8)$ & $155.0(21.8)$ & 0.431 \\
\hline DBP, mmHg, mean (SD) & $83.7(11.3)$ & $83.9(11.9)$ & 0.480 \\
\hline BMI, $\mathrm{kg} / \mathrm{m}^{2}$, mean (SD) & $26.9(4.1)$ & $26.6(4.3)$ & 0.015 \\
\hline Current smoking, $\mathrm{n}(\%)$ & $1086(26.0)$ & $472(28.9)$ & 0.025 \\
\hline \multicolumn{4}{|l|}{ Antihypertensive medications: } \\
\hline Beta-blockers, n (\%) & $1117(26.8)$ & $385(23.6)$ & 0.013 \\
\hline Diuretics, n (\%) & $1656(39.7)$ & $702(43.0)$ & 0.021 \\
\hline ACE inhibitors, $\mathrm{n}(\%)$ & $664(15.9)$ & $287(17.6)$ & 0.122 \\
\hline ARBs, n (\%) & $89(2.1)$ & $27(1.7)$ & 0.241 \\
\hline Calcium channel blockers, n (\%) & $1050(25.2)$ & $408(25.0)$ & 0.895 \\
\hline
\end{tabular}

Abbreviations: SD: Standard Deviation; n: number; TIA: Transient Ischemic Attack; MI: Myocardial Infarction; DM: Diabetes Mellitus; SBP: Systolic Blood Pressure; DBP: Diastolic Blood Pressure; BMI: Body Mass Index; ACE inhibitors: Angiotensin Converting Enzyme Inhibitors; ARBs: Angiotensin Receptor Blockers. 
Supplementary Table 2. Comparison of annual changes in cognitive scores between low and middle thirds of spatial QRS-T angle

\begin{tabular}{lcc}
\hline & Difference of low and middle thirds $(95 \%$ CI) & p-value \\
\hline Stroop, seconds & $0.13(-0.023,0.49)$ & 0.479 \\
LDCT, digits coded & $0.004(-0.08,0.09)$ & 0.924 \\
PLTi, pictures remembered & $-0.02(-0.04,0.02)$ & 0.229 \\
PLTd, pictures remembered & $0.006(-0.05,0.06)$ & 0.832 \\
\hline
\end{tabular}

Analyses were performed in the fully adjusted model

Abbreviations: LDCT: Letter Digit Coding Test; PLTi: Picture-Word Learning Test immediate; PLTd: Picture-Word Learning Test delayed. 
Supplementary Table 3. The estimates $(\beta)$ and $95 \%$ confidence intervals for cross-sectional and longitudinal analyses

\begin{tabular}{|c|c|c|c|}
\hline & $\begin{array}{c}\text { Cross-sectional } \\
\text { Estimate (95\% CI) }\end{array}$ & $\begin{array}{c}\text { Change over time } \\
\text { Estimate (95\% CI) }\end{array}$ & $\begin{array}{c}\text { Additional annual change } \\
\text { Estimate (95\% CI) }\end{array}$ \\
\hline \multicolumn{4}{|c|}{ Stroop test, seconds: } \\
\hline Model 1* & $0.002(0.00001,0.004)$ & $0.004(0.0006,0.007)$ & $0.0004(-0.000007,0.0008)$ \\
\hline Model 2* & $0.001(-0.001,0.003)$ & $0.004(0.0007,0.007)$ & $0.0004(-0.000006,0.0008)$ \\
\hline \multicolumn{4}{|c|}{ LDCT, digits coded: } \\
\hline Model 1 & $-0.042(-0.086,0.002)$ & $-0.312(-0.37,-0.25)$ & $-0.0106(-0.018,-0.003)$ \\
\hline Model 2 & $-0.031(-0.076,0.013)$ & $-0.312(-0.37,-0.25)$ & $-0.0106(-0.018,-0.003)$ \\
\hline \multicolumn{4}{|c|}{ PLTi, pictures remembered: } \\
\hline Model 1 & $-0.006(-0.018,0.006)$ & $0.022(-0.002,0.047)$ & $-0.0049(-0.008,-0.002)$ \\
\hline Model 2 & $-0.005(-0.017,0.007)$ & $0.022(-0.002,0.047)$ & $-0.0049(-0.008,-0.002)$ \\
\hline \multicolumn{4}{|c|}{ PLTd, pictures remembered: } \\
\hline Model 1 & $-0.005(-0.022,0.011)$ & $-0.031(-0.067,0.005)$ & $-0.0055(-0.098,-0.001)$ \\
\hline Model 2 & $-0.001(-0.018,0.016)$ & $-0.031(-0.067,0.005)$ & $-0.0055(-0.098,-0.001)$ \\
\hline \multicolumn{4}{|c|}{ * estimates and $95 \%$ CIs for the natural log-transformed values of Stroop test. } \\
\hline \multicolumn{4}{|c|}{$\begin{array}{l}\text { The term cross-sectional represents the cross-sectional association between spatial QRS-T } \\
\text { angle and cognitive function at baseline. The term changes over time represents the annual } \\
\text { changes of cognitive scores during follow-up. The term additional annual change represents } \\
\text { the extra yearly change in cognitive scores per } 10 \text { degree increase in the spatial QRS-T angle } \\
\text { values. Model } 1 \text { is adjusted for age, sex, country, education and version of cognitive tests where } \\
\text { appropriate; Model } 2 \text { is additionally adjusted for history of vascular disease, history of diabetes, } \\
\text { systolic and diastolic blood pressure, body mass index, smoking status, antihypertensive } \\
\text { medications and statin treatment groups. Abbreviations: LDCT: Letter Digit Coding Test; } \\
\text { PLTi: Picture-Word Learning Test immediate; PLTd: Picture-Word Learning Test delayed. }\end{array}$} \\
\hline
\end{tabular}


Supplementary Table 4. Cognitive function in relation to spatial QRS-T angle during followup, using cut-offs from previous studies

\begin{tabular}{|c|c|c|c|c|}
\hline & \multicolumn{3}{|c|}{ Spatial QRS-T angle thirds } & \multirow{3}{*}{ p-value* } \\
\hline & $\begin{array}{l}\text { Normal } \\
\left(0^{\circ}-104^{\circ}\right)\end{array}$ & $\begin{array}{l}\text { Borderline } \\
\left(105^{\circ}-134^{\circ}\right)\end{array}$ & $\begin{array}{c}\text { Abnormal } \\
\left(135^{\circ}-180^{\circ}\right)\end{array}$ & \\
\hline & 3223 & 370 & 579 & \\
\hline \multicolumn{5}{|c|}{ Stroop, seconds, mean annual decline (SE): } \\
\hline Model 1 & $0.536(0.08)$ & $0.933(0.25)$ & $0.954(0.20)$ & 0.055 \\
\hline Model 2 & $0.540(0.08)$ & $0.941(0.25)$ & 0.956( & 0.054 \\
\hline \multicolumn{5}{|c|}{ LDCT, digits coded, mean annual decline (SE): } \\
\hline Model 1 & $-0.362(0.02)$ & $-0.463(0.05)$ & $-0.467(0.04)$ & 0.004 \\
\hline Model 2 & $-0.363(0.02)$ & $-0.465(0.05)$ & $-0.467(0.04)$ & 0.004 \\
\hline \multicolumn{5}{|c|}{ PLTi, pictures remembered, mean annual decline (SE): } \\
\hline Model 1 & $-0.002(0.008)$ & $-0.028(0.02)$ & $-0.059(0.02)$ & 0.001 \\
\hline Model 2 & $-0.002(0.008)$ & $-0.028(0.02)$ & $-0.059(0.02)$ & 0.001 \\
\hline \multicolumn{5}{|c|}{ PLTd, pictures remembered, mean annual decline (SE): } \\
\hline Model 1 & $-0.054(0.01)$ & $-0.100(0.03)$ & $-0.132(0.03)$ & 0.013 \\
\hline Model 2 & $-0.055(0.01)$ & $-0.101(0.03)$ & $-0.133(0.03)$ & 0.013 \\
\hline \multicolumn{5}{|c|}{$\begin{array}{l}\text { *p-values were calculated using the interaction term between continuous values of spatia } \\
\text { QRST angle and time. } \\
\text { Means represent the mean annual decline in the score of each cognitive test. Model 1: adjustec } \\
\text { for age, sex, country, education and version of cognitive tests where applicable; Model } 2 \\
\text { adjusted for all the variables in model } 1+\text { history of vascular disease, history of diabetes } \\
\text { systolic and diastolic blood pressure, body mass index, smoking status, antihypertensive } \\
\text { medications and statin treatment groups. Abbreviations: SE: Standard Error; LDCT: Lette } \\
\text { Digit Coding Test; PLTi: Picture-Word Learning Test immediate; PLTd: Picture-Worc } \\
\text { Learning Test delayed. }\end{array}$} \\
\hline
\end{tabular}


Supplementary Table 5. Cognitive function in relation to spatial QRS-T angle during followup stratified by APOE e4 at baseline

\begin{tabular}{lcc}
\hline & $\begin{array}{c}\text { Spatial QRS-T angle } \\
\text { Beta }(95 \% \text { CI })\end{array}$ & P for interaction \\
\hline $\begin{array}{c}\text { Stroop, seconds* } \\
\text { E4+, } \mathrm{n}=996\end{array}$ & $0.00005(-0.00003,0.0001)$ & \\
E4-, $\mathrm{n}=3063$ & $0.00003(-0.00001,0.00008)$ & 0.540 \\
LDCT, digits coded & & \\
E4+, $\mathrm{n}=996$ & $-0.0009(-0.002,0.0005)$ & \\
E4-, $\mathrm{n}=3063$ & $-0.001(-0.002,-0.0002)$ & \\
PLTi, pictures remembered & & 0.747 \\
E4+, $\mathrm{n}=996$ & $-0.0004(-0.001,0.0002)$ & \\
E4-, $\mathrm{n}=3063$ & $-0.0006(-0.0009,-0.0002)$ & \\
PLTd, pictures remembered & & \\
E4+, $\mathrm{n}=996$ & $0.0002(-0.0007,0.001)$ & \\
E4-, $\mathrm{n}=3063$ & $-0.0009(-0.001,-0.0004)$ & \\
\hline
\end{tabular}

Estimates and 95\% CI for the natural log-transformed values of Stroop test.

Analyses were performed in the fully adjusted models. E4+ carriers include participants with APOE $\mathrm{E}_{4 / 4}, \mathrm{E}_{3 / 4}$ and $\mathrm{E}_{2 / 4}$ alleles.

Abbreviations: LDCT: Letter Digit Coding Test; PLTi: Picture-Word Learning Test immediate; PLTd: Picture-Word Learning Test delayed. 
Supplementary Table 6. Cognitive function in relation to spatial QRS-T angle during followup, after exclusion of participants with cardiovascular co-morbidities at baseline

\begin{tabular}{|c|c|c|c|c|}
\hline & \multicolumn{3}{|c|}{ Spatial QRS-T angle thirds } & \multirow[b]{2}{*}{ p-value* } \\
\hline & Low & Medium & High & \\
\hline \multicolumn{5}{|l|}{ Stroop, seconds, mean (SE): } \\
\hline No history of hypertension $(\mathrm{n}=1579)$ & $0.785(0.20)$ & $0.707(0.21)$ & $1.008(0.20)$ & 0.152 \\
\hline No history of DM ( $n=3745)$ & $0.422(0.13)$ & $0.624(0.13)$ & $0.725(0.13)$ & 0.035 \\
\hline No history of MI $(n=3631)$ & $0.487(0.14)$ & $0.582(0.14)$ & $0.836(0.14)$ & 0.029 \\
\hline No history of stroke or TIA $(n=3742)$ & $0.415(0.14)$ & $0.593(0.14)$ & $0.724(0.14)$ & 0.045 \\
\hline No anti-arrhythmic use $(n=4079)$ & $0.524(0.13)$ & $0.637(0.13)$ & $0.737(0.13)$ & 0.117 \\
\hline \multicolumn{5}{|l|}{ LDCT, digits coded, mean (SE): } \\
\hline No history of hypertension $(\mathrm{n}=1579)$ & $-0.431(0.04)$ & $-0.355(0.04)$ & $-0.418(0.04)$ & 0.943 \\
\hline No history of DM (n=3745) & $-0.326(0.03)$ & $-0.323(0.03)$ & $-0.459(0.03)$ & 0.002 \\
\hline No history of MI $(n=3631)$ & $-0.359(0.03)$ & $-0.338(0.03)$ & $-0.446(0.03)$ & 0.029 \\
\hline No history of stroke or TIA(n=3742) & $-0.345(0.03)$ & $-0.347(0.03)$ & $-0.472(0.03)$ & 0.002 \\
\hline No anti-arrhythmic use $(n=4079)$ & $-0.355(0.03)$ & $-0.347(0.03)$ & $-0.461(0.03)$ & 0.009 \\
\hline \multicolumn{5}{|l|}{ PLTi, pictures remembered, mean (SE): } \\
\hline No history of hypertension $(\mathrm{n}=1579)$ & $0.010(0.02)$ & $-0.035(0.02)$ & $-0.037(0.02)$ & 0.017 \\
\hline No history of DM ( $n=3745)$ & $0.007(0.01)$ & $0.001(0.01)$ & $-0.028(0.01)$ & 0.008 \\
\hline No history of MI $(n=3631)$ & $0.004(0.01)$ & $-0.007(0.01)$ & $-0.037(0.01)$ & 0.001 \\
\hline No history of stroke or TIA $(n=3742)$ & $0.007(0.01)$ & $-0.001(0.01)$ & $-0.034(0.01)$ & 0.002 \\
\hline No anti-arrhythmic use $(n=4079)$ & $0.006(0.01)$ & $-0.008(0.01)$ & $-0.034(0.01)$ & 0.002 \\
\hline \multicolumn{5}{|c|}{ PLTd, pictures remembered, mean (SE): } \\
\hline No history of hypertension $(\mathrm{n}=1579)$ & $-0.010(0.03)$ & $-0.111(0.03)$ & $-0.074(0.03)$ & 0.030 \\
\hline No history of DM ( $\mathrm{n}=3745)$ & $-0.061(0.02)$ & $-0.042(0.02)$ & $-0.088(0.02)$ & 0.040 \\
\hline No history of MI $(n=3631)$ & $-0.066(0.02)$ & $-0.058(0.02)$ & $-0.094(0.02)$ & 0.025 \\
\hline No history of stroke or TIA( $\mathrm{n}=37$ & $-0.053(0.02)$ & $-0.047(0.02)$ & $-0.096(0.02)$ & 0.009 \\
\hline No anti-arrhythmic use $(n=4079)$ & $-0.059(0.02)$ & $-0.052(0.02)$ & $-0.095(0.02)$ & 0.014 \\
\hline
\end{tabular}

*p-values were calculated using continuous values of spatial QRS-T angle.

All analyses were performed in the fully adjusted models (model 2). Abbreviations: SE: Standard Error; PLTi, Picture-Word Learning Test immediate; PLTd, Picture-Word Learning Test delayed; LDCT: Letter-Digit Coding Test; DM: Diabetes Mellitus; MI: Myocardial Infarction; TIA: Transient Ischemic Attack. 